\title{
- OPEN ACCESS \\ Giant coronary artery aneurysms in a 12-week-old infant with incomplete Kawasaki disease
}

\author{
Lucy Guile, ${ }^{1,2}$ Simon Parke, ${ }^{3}$ Alison Kelly, ${ }^{4}$ Robert Tulloh ${ }^{1,5}$
}

\begin{abstract}
${ }^{1}$ School of Clinical Sciences, University of Bristol, Bristol, UK ${ }^{2}$ Department of Paediatric Surgery, Bristol Royal Hospital For Children, Bristol, UK ${ }^{3}$ Department of Paediatrics, Royal Devon and Exeter NHS Foundation Trust, Exeter, UK ${ }^{4}$ Department of Paediatric Rheumatology, Bristol Royal Hospital for Children, Bristol, UK ${ }^{5}$ Department of Paediatric Cardiology, Bristol Royal Hospital For Children, Bristol, UK
\end{abstract}

Correspondence to Dr Lucy Guile,

lucyguile@doctors.org.uk

Accepted 14 March 2018

Check for updates

To cite: Guile L, Parke $S$, Kelly A, et al. BMJ Case Rep Published Online First: [please include Day Month Year]. doi:10.1136/bcr-2018 224479

\section{SUMMARY}

Kawasaki disease (KD) is an acute inflammatory vasculitis that occurs worldwide and disproportionately affects male children, most commonly between the ages of 6 months and 5 years. KD can present with only a few features and thus be difficult to diagnose, particularly in the youngest and oldest patients. We describe a 12-week-old Caucasian female infant who presented with rash and fever but no other features of KD, who developed giant coronary artery aneurysms. Considering how common is the presentation of a febrile infant with a rash, this case highlights the importance of considering KD early in the differential diagnosis for any infant with unexplained fever. Furthermore, it emphasises how echocardiography can help in the investigation of a febrile child with no clear source of infection.

\section{BACKGROUND}

Kawasaki disease (KD) is an acute inflammatory vasculitis that preferentially affects medium-sized arteries, particularly the coronary arteries. ${ }^{1}$ It is the leading cause of acquired cardiac disease in children in developed countries. ${ }^{2}$ It is more common in boys than girls, and in those of Asian ethnicity. ${ }^{3}$ The aetiology is unclear, but epidemiological features such as the development of clusters of disease has led to the suggestion that an infectious or agent or toxin may be implicated. ${ }^{4}$ Most cases occur in children between 6 months and 5 years of age, but younger infants can also be affected..$^{5}$ Although most patients recover fully, a proportion develops coronary artery aneurysms, which can result in severe acute and long-term sequelae. Aneurysms are more common in those patients in whom treatment is delayed or missed. Extremes of age have been identified as risk factors for coronary artery aneurysm development. ${ }^{6}$

Coronary artery aneurysms develop in up to $25 \%$ of untreated cases of KD with $2 \%$ to $3 \%$ of untreated cases dying due to coronary vasculitis. ${ }^{1}$ Coronary artery dimensions are assessed in the UK by calculation of Z-score. ${ }^{78}$ A minority of patients develop giant coronary artery aneurysms; a recent study found an incidence of $2.6 \%$ in a cohort of American children with KD where giant aneurysm was defined as a maximum $\mathrm{Z}$-score $\geq 10$. Giant coronary artery aneurysms are associated with $29 \%$ to $48 \%$ risk of adverse coronary artery events, including thrombosis, stenosis, myocardial infarction and death. ${ }^{9}$
The key features of Kawasaki disease are ${ }^{1}$ :

- fever: duration of 5 days or more, plus

- conjunctivitis: bilateral, non-suppurative

- cervical lymphadenopathy (often single and large)

- rash: polymorphous

- changes to lips or oral mucosa

- changes to extremities

The diagnosis of complete KD requires fever plus four of the other above features to be present-although not necessarily at the same time. However, it is recognised that KD may present with fewer features and that these cases remain at risk of developing coronary artery aneurysms. Thus, patients with some of the above features-along with evidence of systemic inflammation (such as elevated C-reactive protein (CRP) or erythrocyte sedimentation rate, or leucocytosis) — may be diagnosed with incomplete KD. Echocardiography may show evidence of coronary vasculitis. If present, this confirms the diagnosis, but a normal echocardiogram does not rule out KD. ${ }^{1}$

As illustrated by this case, young infants are more likely than older children to present without the expected features of $\mathrm{KD}$, putting them at greater risk of delayed diagnosis and associated sequelae. $^{10}$

\section{CASE PRESENTATION}

A 12-week-old Caucasian infant was admitted to hospital with a history of fever and vomiting. The illness had started 5 days earlier with diarrhoea and a non-specific rash on her abdomen and back.

No fevers were noted by the parents until the day of admission, on which she vomited and had a low-grade fever of $37.8^{\circ} \mathrm{C}$, prompting her parents to bring her to the emergency department. There was no history of infectious contact. She had been born at $41+2$ weeks gestation via ventouse delivery, had no previous medical problems and was up to date with immunisations.

Clinical examination on admission identified a high fever of $38^{\circ} \mathrm{C}$, and a blanching erythematous rash over her whole body which resolved shortly after admission.

\section{INVESTIGATIONS}

Admission blood results in her local hospital showed a normal white cell count of $11.7 \times 10^{9} / \mathrm{L}$ but an elevated CRP of $64 \mathrm{mg} / \mathrm{L}$. Blood platelets were high at $657 \times 10^{9} / \mathrm{L}$ and haemoglobin 


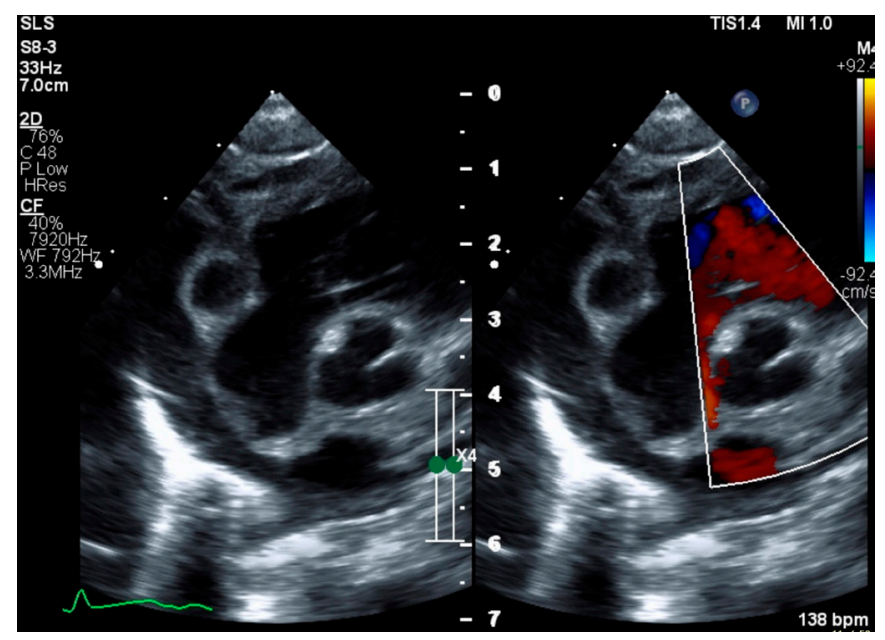

Figure 1 Pericardial effusion in short axis.

was slightly low at $10.1 \mathrm{~g} / \mathrm{dL}$. Alanine transferase, bilirubin and albumin were normal.

Urine dip, viral screen and initial chest radiograph were all normal. Initial and repeat lumbar punctures were unremarkable.

The patient developed recurrent fevers over $38^{\circ} \mathrm{C}$, which did not settle in spite of treatment for presumed bacterial sepsis with intravenous ceftriaxone. One set of blood cultures grew Moraxella osloensis, so a 3-day course of azithromycin was added, but this organism was subsequently felt likely to be a contaminant. There were no other positive microbiology or virology investigations.

There was no lymphadenopathy, joint problems or desquamation of the extremities. Ultrasound examination of the abdomen and renal tract on day 11 of fever showed a grossly distended gallbladder. The same day an echocardiogram was performed, revealing a global pericardial effusion and aneurysmal right and left coronary arteries.

The patient was transferred to a tertiary cardiology centre for management of presumed incomplete KD. The echocardiogram was repeated, confirming these findings, with a pericardial effusion of $8 \mathrm{~mm}$ (figure 1), impaired myocardial function (fractional shortening 26\%) and coronary artery Z-scores of +26 and +20.5 for the right (figure 2 ) and left (figure 3 ) coronary arteries, respectively, indicative of giant coronary artery

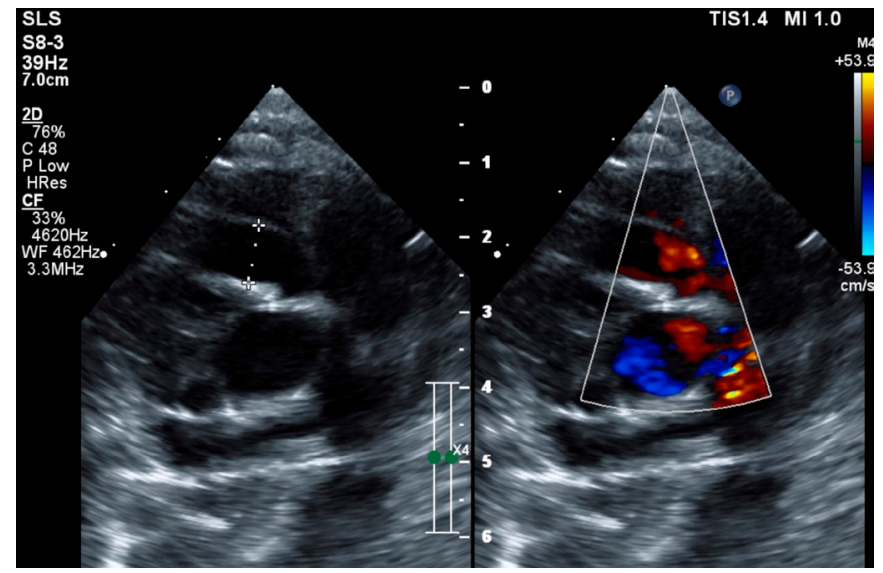

Figure 2 Right coronary artery.

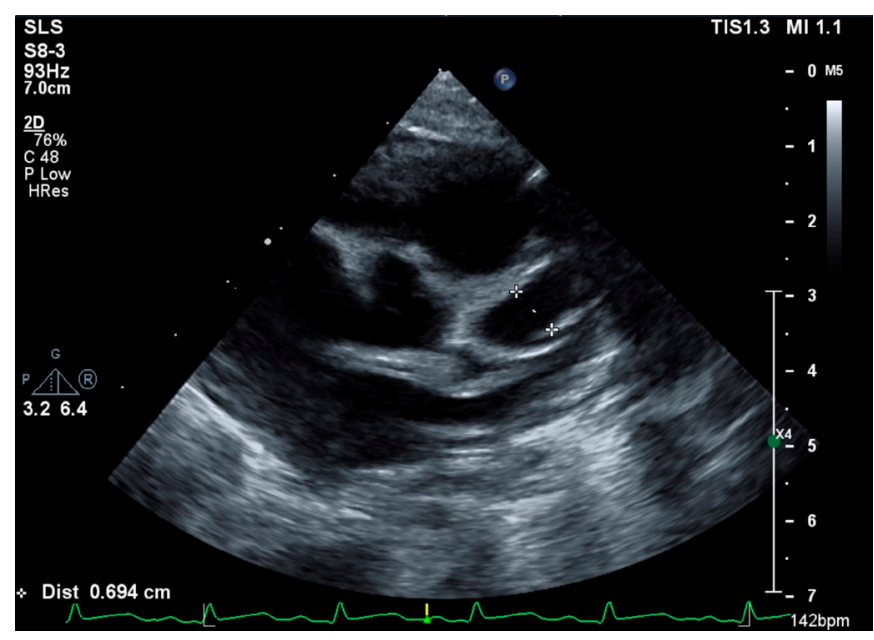

Figure 3 Left coronary artery.

aneurysms. It was possible to visualise the dilated right coronary artery, left anterior descending artery and circumflex artery down to the ventricular apex.

\section{DIFFERENTIAL DIAGNOSIS}

Prior to echocardiography:

- Bacterial sepsis

- Viral infections, such as enterovirus, adenovirus, norovirus These more common childhood conditions present with similar non-specific features, such as fever and rash.

\section{TREATMENT}

Intravenous immunoglobulin $2 \mathrm{~g} / \mathrm{kg}$ (single dose) and highdose aspirin $7.5 \mathrm{mg} / \mathrm{kg}$ every 6 hours were started prior to transfer to the cardiology centre. Methylprednisolone $(20 \mathrm{mg} /$ $\mathrm{kg}$ daily intravenously) and intravenous heparin (infusion titrated to achieve therapeutic anti-Xa levels) were initiated at the tertiary centre, and high-dose aspirin continued. The patient required a second dose of intravenous immunoglobulin 5 days after the initial dose for recrudescence of fever. She received a blood transfusion for anaemia. She was discharged on low-dose aspirin (5 mg/kg daily), subcutaneous enoxaparin, a weaning dose of prednisolone and ranitidine.

\section{OUTCOME AND FOLLOW-UP}

The patient was discharged 25 days after her initial presentation to hospital. Predischarge echocardiogram showed good biventricular function, reducing pericardial effusion and no evidence of coronary thrombus. ECG showed no evidence of ischaemia. CRP had peaked 11 days after the onset of fever at $154 \mathrm{mg} / \mathrm{L}$ and fell to $7 \mathrm{mg} / \mathrm{L} 1$ week after discharge. At clinic review 12 days after discharge, the patient was clinically well and gaining weight. Alongside regular clinical review, she is to be followed up with coronary angiography to document the full extent of coronary involvement.

\section{DISCUSSION}

The diagnostic challenge of this case stemmed largely from the fact that the patient, a Caucasian female infant aged just under 3 months, did not fit the typical KD patient profile. Only $1.6 \%$ of patients with recognised KD are younger than 3 months of age, ${ }^{11}$ and the disease is most common in Asian male children. Furthermore, our patient presented with incomplete $\mathrm{KD}$, with fever and rash-signs that more 
commonly indicate viral infection in this age group-being the only features that fulfilled diagnostic criteria for KD. Nevertheless, she developed giant coronary aneurysms, demonstrating that the most severe sequelae can develop in patients with few of the typical symptoms. Abdominal ultrasound revealed hydrops of the gallbladder, also recognised as a manifestation of KD. ${ }^{12}$

Incomplete cases of $\mathrm{KD}$ present diagnostic difficulty for clinicians, particularly as echocardiography requires paediatric cardiology input. However, a 2013 survey found that 17\% of UK district general hospitals that cared for children did not provide this service. ${ }^{13}$ In the present case, echocardiography was locally available and was instrumental in confirming the diagnosis of $\mathrm{KD}$, highlighting the importance of having this service available to all children. We propose that echocardiography should routinely be considered for any child with persistent unexplained fever, and particularly in children aged under 6 months, to try and prevent the sequelae of unrecognised KD.

\section{Patient's perspective}

\section{Written by the patient's mother and father}

- Our daughter was 3 months old when she was admitted to hospital with sickness, diarrhoea and a high temperature. She had been unwell for 3-4 days by this stage but not admitted to hospital by her general practitioner as the illness was thought to be viral. There had been an initial rash but this disappeared after a few days in hospital.

- Initially she was treated for bacterial meningitis, then Moraxella and then herpes. Throughout her initial 10 days in hospital, she didn't present many of the classic symptoms of Kawasaki apart from the regular spikes in temperature. While obviously unwell she seemed clinically fine which probably delayed the diagnosis of Kawasaki. Her symptoms seemed to suggest a viral infection however the 'not knowing' what she had was difficult as parents.

- Throughout this time, we were worried that our daughter wasn't getting any better and that her case was puzzling the doctors. On day 9 postadmission, the team were beginning to think outside the box and mentioned a rare disease called Kawasaki, although they didn't think it was this. In hindsight this thinking outside the box may have saved her life. Once the echo was performed, the giant aneurysms in her coronary arteries were discovered and intravenous Ig was started within the hour and we were transferred to a specialist children's hospital.

- Once the diagnosis was made, we felt the treatment and care was fantastic and our daughter is now doing as well as she can be. The first 48 hours postdiagnosis were the worst time in our lives.

- We will never know whether an earlier diagnosis would have stopped the aneurysms growing to the size they are; however, we are delighted that our daughter's case is being published and hopefully the insight will help doctors 'think Kawasaki' earlier and diagnose cases to stop them developing into more serious Kawasaki cases.

\section{Learning points}

- Kawasaki disease (KD) can affect children younger than 3 months of age.

- Clinical suspicion is required to recognise KD in the youngest patients, as they are more likely to present with few features of KD.

- Consider KD in the differential diagnosis for any febrile infant who has no clear source of infection.

- Perform echocardiography where there is clinical suspicion of incomplete $\mathrm{KD}$, but recognise that a normal echocardiogram does not exclude the diagnosis.

- Giant coronary artery aneurysms confer a significant risk of major adverse cardiac events. Early treatment with aspirin and intravenous immunoglobulin reduces the risk of these developing. Steroids are indicated in high-risk patients to minimise the progression of coronary artery lesions.

Contributors LG wrote the initial draft. AK, SP and RT amended the draft and approved the final version. RT obtained the echocardiography images.

Funding The authors have not declared any specific grant for this research from any funding agency in the public, commercial or not-for-profit sectors.

Competing interests None declared.

Patient consent Parental/guardian consent obtained.

Provenance and peer review Not commissioned; externally peer reviewed.

Open Access This is an Open Access article distributed in accordance with the Creative Commons Attribution Non Commercial (CC BY-NC 4.0) license, which permits others to distribute, remix, adapt, build upon this work non-commercially, and license their derivative works on different terms, provided the original work is properly cited and the use is non-commercial. See: http://creativecommons.org/ licenses/by-nc/4.0/

(c) BMJ Publishing Group Ltd (unless otherwise stated in the text of the article) 2018. All rights reserved. No commercial use is permitted unless otherwise expressly granted.

\section{REFERENCES}

1 Eleftheriou D, Levin M, Shingadia D, et al. Management of Kawasaki disease. Arch Dis Child 2014;99:74-83.

2 Harnden A, Alves B, Sheikh A. Rising incidence of Kawasaki disease in England: analysis of hospital admission data. BMJ 2002;324:1424-5.

3 Gardner-Medwin JM, Dolezalova P Cummins C et al. Incidence of Henoch-Schönlein purpura, Kawasaki disease, and rare vasculitides in children of different ethnic origins. Lancet 2002:360:1197-202.

4 Rowley AH. Is Kawasaki disease an infectious disorder? Int J Rheum Dis 2018:21:20-5

5 Harnden A, Tulloh R, Burgner D. Kawasaki disease. BMJ 2014;349:95336.

6 Dimitriades VR, Brown AG, Gedalia A. Kawasaki disease: pathophysiology, clinical manifestations, and management. Curr Rheumatol Rep 2014; 16:423.

7 Son MBF, Gauvreau K, Kim S, et al. Predicting Coronary Artery Aneurysms in Kawasaki Disease at a North American Center: An Assessment of Baseline z Scores. J Am Heart Assoc 2017;6:e005378.

8 Chubb H, Simpson JM. The use of Z-scores in paediatric cardiology. Ann Pediatr Cardiol 2012:5:179-84

9 McCrindle BW, Rowley AH, Newburger JW, et al. Diagnosis, treatment, and long-term management of Kawasaki disease: a scientific statement for health professionals from the American Heart Association. Circulation 2017:135:e927-e999.

10 Rowley $\mathrm{AH}$. The complexities of the diagnosis and management of Kawasaki disease. Infect Dis Clin North Am 2015:29:525-37.

11 Cabral M, Correia P, Brito MJ, et al. Kawasaki disease in a young infant: diagnostic challenges. Acta Reumatol Port:36:304-8.

12 Chen CJ, Huang FC, Tiao MM, et al. Sonographic gallbladder abnormality is associated with intravenous immunoglobulin resistance in Kawasaki disease. ScientificWorldJournal 2012;2012:1-5.

13 Andrews $H$, Singh Y. Review of paediatric cardiology services in district general hospitals in the United Kingdom. Cardiol Young 2016;26:528-31. 
Copyright 2018 BMJ Publishing Group. All rights reserved. For permission to reuse any of this content visit http://group.bmj.com/group/rights-licensing/permissions.

BMJ Case Report Fellows may re-use this article for personal use and teaching without any further permission.

Become a Fellow of BMJ Case Reports today and you can:

- Submit as many cases as you like

- Enjoy fast sympathetic peer review and rapid publication of accepted articles

- Access all the published articles

- Re-use any of the published material for personal use and teaching without further permission

For information on Institutional Fellowships contact consortiasales@bmjgroup.com

Visit casereports.bmj.com for more articles like this and to become a Fellow 